\title{
"EU SÓ DESEJO QUE MEUS FILHOS NÃO SOFRAM O QUE EU SOFRI": MEMÓRIAS DE DOR E RESISTÊNCIA DE MULHERES SOBREVIVENTES DO CONFLITO ARMADO COLOMBIANO*
}

\author{
“YO SOLO DESEO QUE MIS HIJOS NO SUFRAN LO QUE SUFRÍ": \\ MEMORIAS DEL DOLOR Y RESISTENCIA DE MUJERES SOBREVIVIENTES DEL \\ CONFLICTO ARMADO COLOMBIANO
}

Ana TAISA da Silva Falcão**

\begin{abstract}
Resumo
Objetivo. apresentar um estudo de caso do conflito armado colombiano a partir da análise do deslocamento forçado e violação dos direitos humanos de mulheres vítimas de grupos paramilitares. O enfoque metodológico do artigo está nos processos derivados do acordo entre o Governo Uribe (2002-2010) e os grupos paramilitares. Metodología. analisamos os Autos da Corte Constitucional e informes de organizações da sociedade civil referentes às violações dos Direitos Humanos das mulheres no conflito armado colombiano. Resultados. Os resultados alcançados, com base na análise dos documentos e dos testemunhos das vítimas, observam a maneira como a violência contra as mulheres se desenvolveu durante o conflito armado. Conclusão. Concluímos que os testemunhos nos mostram seus principais desejos: por vida digna, por reparação, pela busca por fazer parte de uma comunidade e de pertencimento a um lugar.
\end{abstract}

Palavras chave: deslocamento forçado, violência contra as mulheres, conflito armado e Estado.

\section{Resumen}

Objetivo. presentar un estudio de caso del conflicto armado colombiano a partir del análisis del desplazamiento forzado y violación de los derechos humanos de mujeres víctimas de grupos paramilitares. Metodología. El enfoque metodológico del artículo está en los procesos derivados del acuerdo entre el Gobierno Uribe (2002-2010) y los grupos paramilitares. Analizamos los Autos de la Corte Constitucional e informes de organizaciones de la sociedad civil referentes a las violaciones de los Derechos Humanos de las mujeres en el conflicto armado colombiano. Resultados. Los resultados alcanzados, sobre la base del análisis de los documentos y de los testimonios de las víctimas, observan la manera como la violencia contra las mujeres se desarrolló durante el conflicto armado. Conclusión.

\footnotetext{
* Violeta (não é seu nome real). Entrevista cedida à autora em 20 de agosto de 2016. Bogotá. Esta e outras entrevistas realizadas pela autora fazem parte da investigação de Doutorado em História Social, desenvolvida na Universidade Federal do Rio de Janeiro. O objetivo da tese é analisar os processos de violações dos direitos humanos das mulheres cometidos pelos grupos paramilitares que assinaram um acordo de desarmamento com o Governo Uribe (2002-2010).

** Universidade Federal do Rio de Janeiro (PPGHIS-UFRJ). Rio de Janeiro, Brasil. E-mail: taisafalcao@gmail.com

(1) orcid.org/0000-0003-3010-2967 Google Scholar
} 
Concluimos que los testimonios nos muestran sus principales deseos: por vida digna, por reparación, por la búsqueda por formar parte de una comunidad y de pertenencia a un lugar.

Palabras clave: desplazamiento forzado, violencia en contra las mujeres, conflicto armado y Estado.

\begin{abstract}
Objective. Present a case study of the Colombian armed conflict based on the analysis of forced displacement and violation of the human rights of women victims of paramilitary groups. Methodology. The methodological approach of the article is in the processes derived from the agreement between the Uribe Government (2002-2010) and the paramilitary groups. Therefore, both the migratory flows and the acts of violence that subsidize this work date from the 1990s onwards. Also on the methodology, we analyze the Constitutional Court Autos and reports from civil society organizations regarding violations of the Human Rights of women in the Colombian armed conflict. Results. The results achieved reflect the way violence against women developed during the armed conflict. Conclusion. We conclude that the testimonies show us their main desires: for a dignified life, for reparation, for the search to be part of a community and belonging to a place.
\end{abstract}

key words: forced displacement, violence against women, armed conflict and State.

\title{
Pontos de observação introdutórios
}

A América Latina passou por uma conjuntura de efervescente violência socio-política desde a metade do século XX. As motivações, grosso modo, podem ser medidas, a nível internacional, por sua inserção como território de disputa econômica e ideológica das duas grandes potências do período - Estados Unidos e União Soviética - e, a níveis nacionais, pela proliferação de diversos governos de tipos autoritários e ditatoriais. A opção contrainsurgente das elites latinoamericanas contra a população trabalhadora fez com que as violações dos Direitos Humanos, para a manutenção da ordem capitalista se tornassem práticas políticas de Estados cada vez mais militarizados. No seio dessas práticas de terrorismo de Estado, as mulheres sofreram com a implementação de torturas de tipo sexual em larga escala.

Estamos frente a crímenes de guerra, de una nueva forma de la guerra. La violación y la tortura sexual de mujeres y, en algunos casos, de niños y jóvenes, son crímenes de guerra en el contexto de las nuevas formas de la conflictividad propios de un continente de para-estatalidad en expansión, ya que son formas de violencia inherente e indisociable de la dimensión represiva del Estado contra los disidentes y contra los excluidos pobres y no-blancos; de la para-estatalidad propia del accionar bélico de las corporaciones militares privadas (...). Es necesario recordar 
Eu só desejo que meus filhos não sofram o que eu sofri”: memórias de dor e resistência de mulheres sobreviventes...

y reafirmar que éstos no son crímenes de motivación sexual, como los medios y las autoridades siempre insisten en decir para privatizar y, de esa forma, banalizar este tipo de violencia ante el sentido común de la opinión pública, sino crímenes de guerra, de una guerra que debe ser urgentemente redefinida, analizada bajo una nueva luz y a partir de otros modelos, e incorporada con nuevas categorías jurídicas en el Derecho y, muy especialmente, en el Derecho Internacional, es decir, en el campo de los Derechos Humanos y de la Justicia Humanitaria. (Segato, 2014, p. 345)

Diante do exposto, pretendemos fomentar, com este ensaio, um debate sobre como a violência sexual $^{1}$ e o deslocamento forçado ${ }^{2}$ têm, ao longo da história do conflito armado colombiano, vitimado de forma específica mulheres e meninas, desde uma perspectiva que apresente as origens históricas (na guerra e na paz) da desigualdade de gênero, que promove a violência contra as mulheres, de um lado, e os aspectos históricos e socioeconômicos do conflito armado, que reforçam a desigualdade social, o racismo e potencializam a pobreza na Colômbia, de outro lado.

Sobre o conceito de violência sexual, nos referimos às suas mais variadas formas, tais como o assédio sexual, a mutilação sexual, prostituição forçada, escravidão sexual, gravidez forçada, esterilização forçada, casamento forçado e o estupro, estabelecidas como crimes de lesa humanidade pelo Estatuto de Roma do Tribunal Penal Internacional. O Estatuto de Roma entrou em vigor na Colômbia em 1 de novembro de 2002, com exceção dos temas relacionados aos crimes de guerra, que foram ratificados pela Corte Constitucional sete anos depois.

Para tratar do conceito de deslocadas, nos baseamos na definição estabelecida na Colômbia pela Lei 387, de 1997, aprovada pelo Congresso da República, na qual deslocada é:

(...) toda pessoa que se tenha visto forçada a migrar dentro do território nacional abandonando sua localidade de residência ou atividades econômicas habituais, porque sua vida, sua integridade física, sua segurança ou liberdade pessoais foram vulneradas ou se encontram diretamente ameaçadas, por ocasião de qualquer das seguintes situações: conflito armado interno, distúrbios ou tensões internas, violência generalizada, violações massivas dos Direitos Humanos, infrações ao Direito Internacional Humanitário e outras circunstâncias emanadas das situações anteriores que possam alterar drasticamente a ordem pública. (Ley 387 de 1997)

\footnotetext{
${ }^{1}$ A posição da referida Corte Constitucional sobre o Estatuto de Roma pode ser apreciada na íntegra em: http://www.corteconstitucional.gov.co/relatoria/2012/C-290-12.htm

${ }^{2}$ Lei 387 de 1997. Disponível em: http://www.alcaldiabogota.gov.co/sisjur/normas/Norma1.jsp?i=340
} 
A partir da observação da violência sexual em tempos de guerra como um fenômeno histórico, partimos para o estudo de caso no conflito armado colombiano, destacando o seguinte ponto: a violação e deslocamento forçado de mulheres no marco do conflito armado ${ }^{3}$.

O caminho a ser seguido para apresentar este problema fundamenta-se no levantamento da memória das mulheres vítimas do conflito e/ou deslocamento forçado, organizadas em movimentos de mulheres e de deslocados. Para a realização deste projeto, durante o período de 9 a 26 de agosto de 2016, estivemos em contato com mulheres vítimas de violência e deslocamento forçado. Durante este período levantamos cerca de 5 horas de gravação, divididas em 18 entrevistas. Optamos por abordar aqui os testemunhos de duas das 18 entrevistadas, por uma questão de recorte temático e agregamos testemunhos publicados em informes de ONGs e em informes do Centro Nacional de Memória Histórica.

Caminhando na mesma via da memória das mulheres estão as fontes relacionadas com as políticas de governo frente ao enfrentamento da violência contra as mulheres durante o ou como consequência do - conflito armado, tais como os Autos da Corte Constitucional. Soma-se neste panorama de fontes a produção de informes realizados pela sociedade civil, notadamente os movimentos de mulheres.

O presente documento está dividido em quatro partes, sendo a primeira de caráter introdutório, onde apresentamos as motivações, as fontes e a linha narrativa que optamos ao desenhar este trabalho. Já num segundo momento, o primeiro de análise do assunto concretamente, nós descrevemos o conflito armado colombiano em diálogo com a orientação teórica do trabalho, dando ênfase nas análises dos conceitos de guerra e violência.

Em seguida, na terceira parte da pesquisa, nós articulamos relatos de mulheres sobreviventes com as fontes auxiliares, tais como os documentos do governo colombiano e as investigações realizadas por ONGs de mulheres. É importante destacar que, em geral, os documentos utilizados tratam do panorama nacional da relação entre gênero e guerra no conflito armado, o que, em determinados momentos, contrasta com os testemunhos das mulheres sobreviventes, uma vez que suas experiências são regionalizadas e individuais, apesar de estarem inseridas num contexto maior.

Por fim, apresentamos nossas conclusões preliminares apostando na organização, na solidariedade e no associativismo de mulheres como um dos mecanismos mais fortes e sólidos de superação da sua condição de vítimas de violência.

\footnotetext{
${ }^{3}$ Para efeitos desta pesquisa e, obedecendo um dos nossos principais horizontes teóricos que se assenta na busca por apresentar os elementos socioeconômicos do conflito armado desde a ofensiva contrainsurgente das elites colombianas, a fim de garantir do desenvolvimento capitalista no país, violando a população economicamente mais vulnerável.
} 
Eu só desejo que meus filhos não sofram o que eu sofri”: memórias de dor e resistência de mulheres sobreviventes...

\title{
Discussão
}

\section{Violência sociopolítica e guerra prolongada: ou "a política por outros meios"4}

\author{
"O problema da guerra é universalmente reconhecido como um dos \\ problemas mais terríveis que a raça humana atualmente tem de \\ enfrentar. (...) Se diferentes filosofias responderem à pergunta ' $O$ \\ que é a guerra?', poderemos ter na nossa frente diferentes respostas \\ também. (...) A guerra tem múltiplas facetas e que as várias filosofias \\ da guerra refletem simplesmente o fato de diferentes pensadores \\ destacarem facetas diferentes" (Rapoport, 2014, p. 12)
}

Dialogando com o conceito de guerra em Clausewitz, cuja filosofia de guerra é, para Segato ${ }^{55}$, a que orienta os conflitos armados contemporâneos, "a guerra é, pois, um ato de violência destinado a forçar o adversário a submeter-se à nossa vontade” (Clausewitz, 2014, p. 7). Nesse sentido, sendo o fim da guerra a submissão de um dos atores armados aos interesses do vencedor, há, na lógica clausewitzana uma possibilidade de paz que não ocorre na análise de Segato, para quem as guerras atuais não se destinam a alcançar a paz, mas sim a permanecer em constante estágio de conflito. Ao comparar o conceito de guerra instrumental, de Clausewitz, com o conceito de guerra instrumental, de Lênin, Anatole Rapoport, afirma que a instrumentalização da guerra pela classe dominante, na lógica de Lênin, está diretamente relacionada aos lucros que ela traz, ou seja, a guerra é parte fundamental da estratégia acumulação econômica das elites (Rapoport, 2014).

Seguindo essa linha de raciocínio, é possível entender por que as guerras contemporâneas se retroalimentam da violência sem fim - embora não sem objetivo, uma vez que o "sem fim" é igualmente um objetivo - que atende aos interesses, sobretudo, econômicos que a sua manutenção produz. E estes objetivos são políticos, uma vez que se instrumentaliza a estrutura política para garantir o sucesso das operações financeiras que os conflitos armados representam. Os conflitos são os meios violentos, enquanto a política é a via legal que asseguram a sobrevivência de um sistema capitalista em constantes ciclos de crise.

A guerra de uma comunidade (...) surge sempre de uma situação política e só resulta de um motivo político. Aí está por que a guerra é um ato político. (...) A guerra é uma simples continuação da política por outros meios. (...) A guerra não é somente um ato político, mas um verdadeiro instrumento político, uma continuação das relações políticas. (...) A intenção política é o fim, enquanto a guerra é o meio, e não se pode conceber o meio independentemente do fim. (Clausewitz, 2014, p. 26)

\footnotetext{
${ }^{4}$ Para melhor compreensão do conceito citado, ver: Clausewitz (2014). Ver também: Schmitt (1992).

${ }^{5}$ Para Segato (2014), "más con Clausewitz que con Foucault, hoy la guerra aflora y se vuelve conspicua como la materialidad última e irreductible horizonte de toda política, es decir, como la política por otros medios” (p. 341).
} 
O cerne dessa reflexão está exatamente na sua longevidade, pois diversas vezes na história contemporânea da Colômbia a paz surgiu como pauta de debates entre o Estado e os agentes da violência (não desconsiderando o próprio Estado, através de seus aparelhos de repressão, como agente violento do conflito). Em outubro de 2016, o resultado do Plebiscito demonstrou que ainda há setores da sociedade colombiana, por ação ou omissão, que não desejam a paz. Nesse sentido, Segato (2014) afirma que:

(...) as guerras atuais têm se transformado de forma substantiva. Não se destinam a um término e sua meta não é a paz, em quaisquer de suas versões. O projeto da guerra é, hoje, para seus administradores, um projeto a longo prazo. (p. 341)

O historiador Sánchez (2012) afirmou que, para os colombianos com menos de 50 anos, a guerra é uma realidade constante. Para Segato, isso não ocorre como uma consequência social das guerras, pelo contrário, "o plano é que [as guerras] se transformem, em muitas regiões do mundo, em uma forma de existência” (Segato, 2014, p. 341). Tal constatação se torna especialmente dolorosa se pensarmos principalmente nas experiências traumáticas das pessoas que vivem toda uma vida nas zonas onde o conflito armado é mais acentuado. A guerra é, nesse sentido, parte fundamental do planejamento estrutural de setores da economia - nacional e internacional - que atuam de forma legal e ilegal. É uma guerra estrutural, com variadas formas de violência, desde a violência física às violências simbólica e econômica.

\begin{abstract}
Aqui, estamos falando sobre a violência inerente a um sistema: não só de violência física direta, mas também das formas mais sutis de coerção que sustentam as relações de dominação e de exploração, incluindo a ameaça de violência. (...) É necessário historicizar minuciosamente a noção de violência objetiva, que assumiu uma nova forma com o capitalismo. (...) É demasiadamente simplista afirmar que o espectro desse monstro autogenerativo que segue o seu caminho ignorando qualquer preocupação humana ou ambiental seja uma abstração ideológica e que por trás dessa abstração há pessoas reais e objetivos naturais em cujos recursos e capacidades produtivas se baseia a circulação de capital, alimentando-se deles como um parasita gigante. (Žižek, 2014, p. 27)
\end{abstract}

A guerra atualmente, sob a ótica que Segato (2014) nos apresenta, é uma guerra "despojadora e lucrativa” (p. 342), que transforma lugares como o nosso continente em territórios de espoliação mediante recurso indiscriminado da violência, o que reforça o argumento de Clausewitz, para quem, desde que se deseje alçar um objetivo, todo recurso de violência é válido. Em Clausewitz (2014) "a guerra não é a ação de uma força viva sobre uma massa inerte”, pois “a não resistência absoluta seria a negação da guerra”, logo, "ela é sempre a colisão de duas forças vivas"; "a ação" da guerra "é recíproca” (p. 11). Aqui se encontra a diferença 
Eu só desejo que meus filhos não sofram o que eu sofri”: memórias de dor e resistência de mulheres sobreviventes...

fundamental entre o que é a guerra para Clausewitz e o que são as guerras contemporâneas, para Segato (2014), pois:

(...) en este nuevo escenario bélico mundial, las guerras de nuestro continente son de tipo no convencional, el espacio más violento del planeta en términos de guerras no libradas formalmente entre estados. Es muy importante también hacer notar que no es ésta una agresión al cuerpo antagonista, al cuerpo del sicario de la facción enemiga, sino otra cosa. Los agredidos son cuerpos frágiles, no son cuerpos guerreros. (...) En la acción para-estatal de estos grupos es todavía más crítica la necesidad de demostrar esa ausencia de límites en la ejecución de acciones crueles (...) Por un lado, la truculencia es la única garantía del control sobre territorios y cuerpos, y de cuerpos como territorios, y, por el otro, la pedagogía de la crueldad es la estrategia de reproducción del sistema. (p. 341)

A violência que se emprega aqui faz de nosso continente um reprodutor de múltiplas violências que afetam diretamente a vida da população civil, em geral, e das mulheres - cuja intersecção de classe, gênero e raça/etnia potencializa sua vulnerabilidade social -, em particular. Sobre isso, cabe sempre reforçar:

Desde las guerras tribales hasta las guerras convencionales que ocurrieron en la historia de la humanidad hasta la primera mitad del siglo $\mathrm{XX}$, el cuerpo de las mujeres, qua territorio, acompañó el destino de las conquistas y anexiones de las comarcas enemigas, inseminados por la violación de los ejércitos de ocupación. Hoy, ese destino ha sufrido una mutación por razones que tenemos pendiente examinar: su destrucción con exceso de crueldad, su expoliación hasta el último vestigio de vida, su tortura hasta la muerte. La rapiña que se desata sobre lo femenino se manifiesta tanto en formas de destrucción corporal sin precedentes como en las formas de trata y comercialización de lo que estos cuerpos puedan ofrecer, hasta el último limite. A pesar de todas las victorias en el campo del Estado y de la multiplicación de leyes y políticas públicas de protección para las mujeres, su vulnerabilidad frente a la violencia ha aumentado, especialmente la ocupación depredadora de los cuerpos femeninos o feminizados en el contexto de las nuevas guerras. (Segato, 2014, p. 342)

Ora, não se trata, então, de compreender a guerra a partir da relação de força entre seus agentes de violência, uma vez que, algo que já é consenso para o conflito armado colombiano, a violência tem sido empregada, contra aquela "massa inerte" da filosofia de guerra clausewitzana. E por que essa violência contemporânea é "despojadora e lucrativa”? Porque as 
guerras contemporâneas e o conflito armado colombiano dentre elas, lançam mão de diversas manifestações de violência que aumentam o lucro dos "administradores" das guerras. Assim, "a guerra nunca é deflagrada subitamente e a sua extensão não é obra do acaso" (Clausewitz, 2014, p. 13).

Ou seja, quando falamos que a manutenção histórica da violência na Colômbia atende a interesses macroeconômicos do Capital (legal e ilegal), estamos tratando de setores da economia que lucram com a proliferação da pobreza, mediante deslocamento forçado e expropriação de terras de campesinos, comunidades afro e indígenas, e lucram com a corrupção dos aparelhos do Estado, mediante coparticipação nos lucros da guerra. "É aí que reside a violência sistêmica fundamental do capitalismo (...): essa violência não pode ser atribuída a indivíduos concretos e às suas 'más' intenções, mas é puramente objetiva, sistêmica, anônima” (Žižek, 2014, p. 26).

Ou seja, "são formas de violência inerentes e indissociáveis da dimensão repressiva do Estado contra os dissidentes e contra os excluídos pobres e não-brancos” (Segato, 2014, p. 345). Sobre a violência sociopolítica na Colômbia, cremos ser ela parte de uma violência - que temos apresentado a partir da leitura de especialistas em guerras, conflitos armados e violência - que é inerente e inseparável da prática repressora dos Estados Latino-americanos, cujo terrorismo de Estado é lançado diretamente contra a população pobre, negra, as mulheres, os excluídos de um modo geral.

\title{
Violência contra as mulheres, deslocamentos forçados e memória
}

Antes de mais nada, é importante dizer que a violência sexual em situações de conflitos armados só é possível de existir enquanto prática "habitual, estendida e sistemática" (Corte Constitucional, 2008), porque já opera em larga escala como um fenômeno social no cotidiano das sociedades. Em especial em sociedades como as nossas, latino-americanas, que encabeçam os principais índices internacionais de estupros, violência doméstica e feminicídio ${ }^{66}$.

\begin{abstract}
Se presentan recurrentemente episodios de violencia familiar en las trayectorias de las mujeres afectadas por la violencia política "pública". Son historias de padres borrachos que se gastan la plata del mercado; de maltrato a la madre; de agresividad y dominio total sobre las hijas y a veces de acoso sexual hacia ellas. La violencia intra-familiar lleva a la niña o a la joven mujer, a buscar cómo escapar a las insoportables tensiones de su "mundo chico": lo busca en una relación precoz con otro hombre; o muy frecuentemente, en el ingreso a la guerrilla. (Meertens, 1995, p. 98)
\end{abstract}

\footnotetext{
${ }^{6}$ A título de comparação, no Brasil, apenas para o ano de 2015, o país apresentou um índice de um estupro a cada 11 minutos - ou seja, cinco estupros por hora -, dos quais 70\% foram cometidos contra crianças e adolescentes; $15 \%$ envolveram dois ou mais agressores; cerca de 70\% foram cometidos por parentes das vítimas. Para maiores informações, ver: Fórum Brasileiro de Segurança Pública. $10^{\circ}$ Anuário Brasileiro de Segurança Pública. 2016.
} 
Eu só desejo que meus filhos não sofram o que eu sofri”: memórias de dor e resistência de mulheres sobreviventes...

Há um esforço por parte de intelectuais ${ }^{7}$ e defensores dos Direitos Humanos ${ }^{8}$ de denunciar as violações dos direitos das mulheres na Colômbia e oferecer propostas teóricas e metodológicas de se compreender e enfrentar a violência sexual. As pesquisadoras colombianas intensificam sua participação nos debates sobre o conflito armado, a partir da década de 1990, com o objetivo de denunciar as violações dos direitos humanos das mulheres, em que a violação de seus corpos se converte em objetivo militar. Num contexto em que o conflito armado modifica suas estratégias de combate, deixando o ataque direto entre combatentes a segundo plano, passando a priorizar a disseminação da violência contra a população civil, "as mulheres deixam de ser só objeto de agressão sexual, e passam a ser tanto objetivo militar como de colonização física" (Gómez y Wills, 2012, p. 271).

Numa pesquisa organizada pela Ruta Pacífica de Mujeres e realizada entre os anos de 2001 $2009^{9}$, em diversos municípios em que havia a incidência de grupos armados em conflito, seja exército, polícia, insurgência ou paramilitares, foi constatado que cerca de 489.687 mulheres foram vítimas de alguma forma de violência sexual durante os nove anos do estudo.

Se trata de um tipo de violência que, em tempos de paz ou de guerra, sua quantificação é frequentemente difícil, pois em geral as vítimas tendem, por medo, estigmatização ou ameaça, a não denunciar o ocorrido. Existem diversos relatórios e trabalhos publicados na Colômbia sobre a violência sexual no conflito armado, todos afirmam, entretanto, que as limitações relacionadas à subnotificação da violência sexual ainda é uma barreira a se enfrentar.

No informe ¡Basta ya! (CNMH, 2013), que aponta a incidência da violência sexual no conflito armado, de 1985 até 2013, com base no Registro Único de Vítimas (RUV), 1.754 mulheres declararam ter sofrido violência sexual.

Las 1.754 víctimas incluidas en el RUV (733 entre 1985 y 2012, más 821 sin año de ocurrencia identificado) contrastan con las 96 confesadas por los paramilitares en sus versiones libres en el marco de la Ley 975 del 2005 y las 142 documentadas por varias organizaciones de Derechos Humanos para el Anexo Reservado del Auto 092 del 2008 de la Corte Constitucional sobre violencia sexual. (CNMH, 2013, p. 78)

Os dados da Unidad para la Atención y Reparación Integral a las Víctimas -UARIV- (2011) referentes aos crimes perpetrados contra a integridade e a liberdade sexual dos indivíduos, nos mostram que 15.785 mulheres alegam ter sofrido dessa modalidade de violência. Ainda

\footnotetext{
${ }^{7}$ Para a realização deste trabalho destacamos dois trabalhos em especial: Meertens (2000) e Restrepo (2007).

${ }^{8} \mathrm{O}$ volume de trabalhos realizados por organizações colombianas (estatais ou ONGs) e internacionais é vasto, mas destacamos aqui alguns estudos especiais: ACNUR (2007), Amnistía Internacional (2011) e CNMH (2013).

${ }^{9}$ Para maiores informações sobre a pesquisa, ver: Ruta Pacífica de Mujeres. Violaciones y otras violencias: saquen mi cuerpo de la guerra. Violencia sexual en contra de las mujeres en el contexto del conflicto armado. Primera Encuesta de Prevalencia - Resumen ejecutivo, 2011.
} 
assim, se comparado com os números relacionados com outros tipos de violência, tais como o deslocamento forçado, em que o número de mulheres vítimas desse delito é de 3.493.124, podemos perceber que de fato a denúncia da violência sexual segue constituindo um impasse para a formulação de estatísticas frente a esse problema.

Apesar dos números sobre violência sexual seguirem subnotificados e com altos índices de impunidade para os violadores, as iniciativas de memória demonstram que, fora do ambiente oficial de denúncia, as mulheres se sentem à vontade e desejam falar de suas experiências de violação.

Tomamos como exemplo o testemunho de uma das mulheres vítimas de violação e deslocamento forçado que nos cederam suas histórias de vida.

Em 2005 sofri meu segundo deslocamento forçado, foi num domingo de agosto, quando por volta das cinco da tarde chegaram três homens encapuzados em nossa casa e eu estava com minha filha de 14 anos. Meus outros filhinhos não estavam na casa no momento. Foi quando chegaram os homens encapuzados e me levaram para fora, onde ficavam as bananeiras e eu fui violada... E a minha filha, quando eu voltei para a casa, também havia sido violada. No dia seguinte, juntamos nossas coisas e nos mudamos para um vilarejo rio acima. (Entrevista cedida à autora, comunicação pessoal, 21 de agosto de 2016)

As experiências de violação e, muitas vezes consequentemente, deslocamento forçado de mulheres compõem um conjunto de violações dos direitos humanos cometidos durante o conflito armado. No caso que citamos acima, a vítima reconheceu seus violadores como membros de um grupo paramilitar do Departamento de Meta. Casos como este são muito frequentes quando se faz um levantamento do conflito desde os testemunhos das vítimas, sem estigmatiza-las.

Os relatos registrados pelo Centro Nacional de Memória Histórica mostram a utilização da violência sexual por parte dos grupos paramilitares como uma arma deliberada para torturar as mulheres e espalhar terror nas suas comunidades, como no caso abaixo:

(...) me llevó a una casa en El Placer [alias El Indio]. Cuando entré me encontré con cuatro mujeres de distintas edades, unas muy jóvenes y otras ya adultas. (...) Cuando nos estaban violando nos decían 'si no quieren que las echemos al hueco, ¡cállense!'. Ese espacio visible y amenazante me acompañó todo el año que duré encerrada en esa casa. Llegaban borrachos, drogados, nos sacaban al patio, nos apuntaban con armas cortas y largas, y nos cogían a la fuerza hasta encerrarnos en el cuarto que ellos escogían. Una vez me tocó con tres hombres al mismo tiempo. (...) llegaban tirando puertas y entraban al cuarto de 
Eu só desejo que meus filhos não sofram o que eu sofri”: memórias de dor e resistência de mulheres sobreviventes...

la que quisieran y ahí caían. Se iban después de tener sexo. Era muy duro, no podíamos salir a ninguna parte, pasábamos el día lavándoles los uniformes, limpiando la casa y cocinando para ellos... como una 'mujer'. Recuerdo que una muchacha de 15 años se suicidó. No aguantó. La mujer mayor era la que nos daba ánimo. (CNMH, 2012, p. 208)

Nas localidades em que a população ficou sob domínio de grupos paramilitares ou em áreas de conflito entre os diferentes grupos armados, a violência se tornou uma constante para toda a comunidade, em geral, e para as mulheres, em particular. A ameaça da violência ou a consolidação da mesma, seja diretamente contra as mulheres ou contra membros da sua família, motivaram outro ato vitimizante: a fuga para outros pontos do país (desplazamiento forzado interno), ou para outros países (refúgio). Nesse momento, um novo ciclo de violências se inicia na vida dessas mulheres frente às incertezas que compõem mudanças bruscas como as que ocorrem em situações como essas. Famílias inteiras se deslocam diariamente no interior do território, ou para fora dele, em busca de segurança, para fugir da violência.

Os motivos que levam tantas pessoas a abandonarem tudo (família, terra, bens, laços comunitários) e seguirem da maneira que for possível para outros lugares são o medo da violência, as constantes ameaças, a violência em si etc.

En Colombia, el desplazamiento forzado - delito de lesa humanidades un fenómeno masivo, sistemático, de larga duración y vinculado en gran medida al control de territorios estratégicos. (...) más allá de la confrontación entre actores armados, existen intereses económicos y políticos que presionan el desalojo de la población civil de sus tierras y territorios. Sucede así con el narcotráfico y sus estructuras de financiación, que han sido definidos en la sostenibilidad y agudización de la violencia sociopolítica en diferentes regiones del país. (...) no se puede dejar de lado intereses provenientes de sectores empresariales que también han contribuido a propiciar el desalojo y apropiación de importantes territorios. (CNMH, 2013, p. 71)

Do mesmo modo que os processos de deslocamento respondem às mudanças nas configurações do conflito armado, que por sua vez, "historicamente se associa com a migração forçada dos habitantes de uma determinada região ou localidade” (Segura e Meertens, 1997, p. 1). Ou seja, conflito e deslocamento forçado mantém uma relação mútua e constante de interação, o que gera, com muita frequência, novos ciclos de deslocamento de populações já deslocadas.

Em entrevistas realizadas com mulheres deslocadas forçadamente pela violência para a realização deste trabalho, o tema dos múltiplos deslocamentos foi uma constante. Dois tipos de deslocamento apareceram com mais frequência: 1) pela pobreza e, consequentemente, 
necessidade de buscar emprego em outras localidades, que em geral eram os primeiros deslocamentos dessas mulheres e; 2) pela violência, seja através de ameaças diretas à vida delas ou suas famílias, seja pela morte de parentes pelo conflito, ou por massacres coletivos em suas cidades. Em alguns casos, a mesma pessoa havia passado por cerca de quatro deslocamentos, somando a procura por trabalho e a fuga da violência.

As narrativas demonstram que o deslocamento forçado na Colômbia já assumiu um caráter vicioso, que, acima de tudo, afeta os mais pobres, os mais vulneráveis, aqueles que, ao fim e ao cabo, não estão ligados diretamente ao conflito armado, mas que, por serem reincidentemente violados por ele, fogem de um lugar ao outro em busca de paz. "Dos mais de cinco milhões de deslocados forçados pelo conflito armado, cerca de 70\% são pessoas de origem campesina, indígena e afrocolombiana” (Alto Comisionado de las Naciones Unidas para los Refugiados ACNUR-, 2007, p. 28).

As comunidades negras ou afrocolombianas são titulares do direito especial ao território, este é um dos direitos (...) dos mais afetados pelo deslocamento. Para a população afrocolombiana o território é um elemento central de sua cultura e sua identidade étnica, por esta razão, o deslocamento de que são vítimas atenta contra sua existência como grupo étnico. (Saldarriaga, 2013, p. 15)

Para as mulheres afrocolombianas, a experiência de deslocamento forçado, que se conjuga com o deslocamento pela pobreza, tem especiais características de (históricas) violências raciais.

Si se tiene en cuenta que un $48 \%$ de los desplazados eran pequeños propietarios, que un $43 \%$ carecían de propiedades (CODHES, 1997), y que en muchos casos debieron abandonar sus pocas pertenencias o venderlas a precios irrisorios, no es de extrañar que queden obligados a insertarse en la ciudad en condiciones de absoluta pobreza. (Bello, 2000, p. 115)

De acordo com a Consultoría para los Derechos Humanos y Dezplazamiento Forzado (CODHES, 2008), cerca de 98\% dos afrocolombianos e afrocolombianas que foram vítimas de deslocamento forçado pela violência do conflito armado vivem abaixo da linha da pobreza e muitos deles em situação de indigência, sem nenhum tipo de oportunidade trabalhista, tampouco de assistência legal.

En términos generales, la inmensa mayoría de la población afrocolombiana, especialmente la que fue forzada a abandonar su territorio debido al conflicto armado, se encuentra marginada de los beneficios del desarrollo, con un bajo nivel de vida, que se evidencia en pobreza, inequidad social, 
Eu só desejo que meus filhos não sofram o que eu sofri”: memórias de dor e resistência de mulheres sobreviventes...

\begin{abstract}
discriminación, mínima inversión en capital humano, a lo que se suma la violencia, siendo su estado uno de los más críticos en la totalidad de la población colombiana. (Saldarriaga, 2013, p. 67)
\end{abstract}

No Auto 092 de 2008, a Corte Constitucional reconhece a ocorrência de violações de tipo específico contra as mulheres motivadas por sua condição de gênero na sociedade colombiana como um todo, e no conflito armado em particular, em que os objetivos - econômicos, políticos e militares - dos grupos armados são alcançados através da materialização da violência contra a população civil e de maneira desproporcionada contra as mulheres. Mediante essa declaração de ciência do impacto desproporcionado, em termos quantitativos e qualitativos, do conflito armado interno e do deslocamento forçado para as mulheres (Corte Constitucional, 2008), a Corte Constitucional elencou dez riscos - "riesgos extraordinarios de género" - específicos que correm as mulheres e meninas nos territórios sob domínio de grupos armados, entendendo a Força Pública como um dos grupos armados do conflito interno.

Os riscos de violência baseada no gênero, aos quais estão sujeitas as mulheres colombianas, de acordo com a Corte Constitucional, podem ser observados no quadro abaixo:

\title{
Quadro 1. Riscos extraordinários violência de gênero no conflito armado
}

\begin{tabular}{|c|c|}
\hline \multicolumn{2}{|r|}{ Fatores de vulnerabilidade de gênero de acordo com o Auto 092/08 } \\
\hline I & Violência sexual, exploração sexual ou abuso sexual; \\
\hline II & $\begin{array}{l}\text { Exploração ou escravização para exercer trabalhos domésticos e papeis } \\
\text { considerados femininos em una sociedade com traços patriarcais, por parte dos } \\
\text { atores armados ilegais; }\end{array}$ \\
\hline III & $\begin{array}{l}\text { Recrutamento forçado de seus filhos e filhas pelos atores armados à margem da } \\
\text { Lei; }\end{array}$ \\
\hline IV & $\begin{array}{l}\text { Riscos derivados do contato ou das relações familiares ou pessoais - voluntárias, } \\
\text { acidentais ou supostas - com os integrantes de algum dos grupos armados ilegais, } \\
\text { ou Força Pública; }\end{array}$ \\
\hline V & $\begin{array}{l}\text { Pertencimento a organizações sociais, comunitárias ou políticas de mulheres, ou } \\
\text { de seus trabalhos de liderança e promoção dos direitos humanos; }\end{array}$ \\
\hline VI & Perseguição e assassinato através de estratégias de controle coercitivo; \\
\hline VII & $\begin{array}{l}\text { Assassinato ou desaparição de seu provedor econômico ou pela desintegração de } \\
\text { seus grupos familiares e de suas redes de apoio material e social; }\end{array}$ \\
\hline VIII & $\begin{array}{l}\text { Desapropriação de suas terras e seu patrimônio com maior facilidade pelos atores } \\
\text { armados ilegais; }\end{array}$ \\
\hline IX & $\begin{array}{l}\text { Condição de discriminação e vulnerabilidade acentuada das mulheres indígenas e } \\
\text { afrodescendentes; }\end{array}$ \\
\hline $\mathrm{x}$ & $\begin{array}{l}\text { Perda ou ausência de seu companheiro ou provedor econômico durante o processo } \\
\text { de deslocamento. }\end{array}$ \\
\hline
\end{tabular}

Fonte: elaboração própria com base nos dados da Corte Constitucional (2008), Auto 092/08. 
Com o objetivo de ratificar a veracidade da existência desses riscos à vida das mulheres que residem nas zonas de conflito ou que sofreram processos de deslocamento forçado, citamos o depoimento de Violeta ${ }^{10}$, em que ela nos conta que no município em que vivia com seu companheiro e um filho, ela possuía um pequeno restaurante. Era uma área de domínio das FARC, no município de Miraflores ${ }^{11}$, e foram os próprios guerrilheiros quem avisaram aos moradores da cidade que o Exército ia ocupar a região e, quando de fato isso ocorreu, sua condição de mulher e dona de comércio foi explorada pelos membros do Exército, que lhe pediam que lhes servisse comida ou lhes emprestasse suas panelas (por serem grandes) e utensílios de cozinha. Segundo Violeta, isso soou para os membros da guerrilha como uma forma de colaboracionismo de sua parte para com os militares, o que desencadeou uma série de eventos de discórdia contra ela em sua comunidade. Inclusive com um senhor que era seu amigo, mas que ela desconhecia o fato de ele ser um membro da guerrilha e ele além de ter-lhe repreendido por “auxiliar” o Exército, posteriormente foi o porta-voz da ameaça de morte que ela sofreu por estar forçadamente colaborando com o Exército.

Note-se que Violeta foi vítima do risco de vulnerabilidade número II, elencado no quadro acima. Há um elemento no caso de Violeta, entretanto, que destoa do texto do risco de vulnerabilidade, que é o fato de ela ter sido vítima de exploração de atividades domésticas, ao ser forçada a cozinhar ou, no mínimo, entregar seus utensílios de cozinha (fonte de sua renda) aos membros do Exército. A diferença entre o que ocorreu com Violeta, com o que ditou a Corte Constitucional como "risco de vulnerabilidade" está no ator armado responsável pela violência, uma vez que o texto do Auto 092/08 diz que se configura como risco de vulnerabilidade a "exploração ou escravização para exercer trabalhos domésticos e papeis considerados femininos em una sociedade com traços patriarcais, por parte dos atores armados ilegais”. Embora esteja claro na história dela que ela foi vítima de uma das violências descritas como iminentes por sua condição de gênero, parece que a Corte Constitucional, no Auto 092 /08, não levou em consideração a possibilidade da Força Pública exercer o mesmo tipo de violência que os demais atores armados à margem da lei.

A narrativa de Violeta ainda acompanha mais três riscos de vulnerabilidade, a saber: "VII) Assassinato ou desaparição de seu provedor econômico ou pela desintegração de seus grupos familiares e de suas redes de apoio material e social”; e "X) Perda ou ausência de seu companheiro ou provedor econômico durante o processo de deslocamento". Isso se deu,

\footnotetext{
${ }^{10}$ Nome fictício. Todos os nomes das entrevistadas foram modificados para sua segurança e de suas famílias. Suas regiões de origem, no entanto, são verdadeiras.

11 "El municipio está localizado al sur oriente del departamento de Boyacá a 1.500 metros sobre el nivel del mar, en la Región Andina y comprende zonas predominante montañosas que hacen parte de la Cordillera Oriental; tiene una extinción de 258 kilómetros cuadrados. Miraflores es el municipio más importante de la Provincia de Lengupá. Esta Provincia comprende los municipios de Berbeo, Campohermoso, Páez, San Eduardo, Rondón y Zetaquira. Miraflores es capital de provincia. La población Mirafloreña está compuesta por 9.901 habitantes distribuidos en la zona rural y urbana, según el dato de población SISBEN año 2005" (http://www.miraflores-boyaca.gov.co/informacion_general.shtml).
} 
Eu só desejo que meus filhos não sofram o que eu sofri”: memórias de dor e resistência de mulheres sobreviventes...

porque no momento em que Violeta, grávida de seu segundo filho, e seu filho mais velho saíram de Miraflores, em 2007, ameaçados de morte pela guerrilha, ela não havia encontrado seu companheiro durante todo o dia e a noite em que ela esteve para fugir. Sendo assim, e especialmente porque o senhor, que era seu "amigo" e que lhe avisou da ameaça de morte que ela sofria, foi assassinado pelas costas pelo Exército próximo de sua casa, o que a fez pensar que o mesmo havia se passado com seu companheiro.

Quando ela chegou a Bogotá, lamentavelmente foi vítima de racismo (risco de vulnerabilidade número IX, "condição de discriminação e vulnerabilidade acentuada das mulheres indígenas e afrodescendentes”), pois é afrocolombiana oriunda do Caribe colombiano, região tradicionalmente ocupada pela população afro e com fortes traços de desigualdade sociorracial. Violeta chegou a dormir na rua, por dois dias, grávida, com uma criança pequena, com fome, sede, sem auxílio e sem ser ouvida pelas pessoas a quem ela pedia socorro. No terceiro dia, uma senhora a acolheu em sua casa e como seu filho estava, para além de fraco de fome, doente pelo frio, essa senhora a levou a um hospital em Bogotá e de lá a encaminhou à Unidad de Víctimas, onde, por uma grande coincidência, ela reencontrou seu companheiro. Em suas palavras:

(...) o papai de meu filho, eu mesma não sabia para onde tinha ido,
pensava que havia sido morto, mas não foi morto! Ele apareceu aqui
em Bogotá, aqui nos encontramos outra vez. [Risos] (...) Eu tinha
dois meses de gravidez e ele soube que eu estava grávida quando nos
encontramos. (Violeta, comunicação pessoal, 20 de agosto de 2016)

Ao identificar os riscos de vulnerabilidade baseados no gênero, a Corte Constitucional, por meio do Auto 092 $\backslash 08$ constatou que a violência sexual no conflito armado constitui situação de gravidade para a integridade das mulheres. Diante dessa constatação, a Corte Constitucional estipulou, com base em informações apresentadas pelas próprias vítimas, pelas organizações que as representam e por organizações dedicadas à sistematização e divulgação dos casos de violência sexual praticados como arma pelos grupos combatentes, um padrão de comportamento violento por parte dos grupos armados. Nesse padrão de comportamento diagnosticado pela Corte Constitucional e divulgado no Auto 092, a violência sexual perpetrada pelos grupos armados aparece como componente do conjunto de violações dos Direitos Humanos empregadas em massacres, desapropriação de terras, pilhagens e destruições de povoados, cometidas contra mulheres adultas, adolescentes e meninas das localidades afetadas pelo conflito. 


\section{Conclusões: a pressão das sujeitas políticas por justiça e reparação}

A mobilização da sociedade civil, protagonizada pelos movimentos de mulheres e defensores dos direitos humanos, nacionais e internacionais, em torno do debate sobre a violência sexual no conflito armado foi tão significativa, ao mesmo tempo em que a violência do conflito se tornava tão alarmante, que a Corte Constitucional emitiu dois Autos para tratar do tema. O primeiro, Auto 092, foi publicado no ano de 2008 e o segundo, o Auto 009 (Corte Constitucional, 2015), foi emitido no ano de 2015, dada a permanência das violências de caráter sexual, mesmo após sete anos de publicação do primeiro Auto. Apesar dos limites ainda presentes no acesso à justiça por parte das mulheres sobreviventes de violência sexual, as publicações dos dois Autos constituem um avanço histórico no que se refere à constatação pública da existência de diversas violências de género como fatos social diretamente relacionado com o conflito armado.

A conjunção entre violência e pobreza na realidade das mulheres deslocadas nos mostrou o aprofundamento dos processos de violação e de novos ciclos de deslocamento forçado como consequência das dinâmicas específicas do conflito armado colombiano. Desde a observação de suas memórias e percepções sobre estes eventos, vemos que as demandas por programas de assistência, reparação e justiça continuam muito altas.

A saída das FARC como um dos agentes armados do conflito é um salto histórico importantíssimo para a superação do deslocamento forçado e da violência, pois o conflito entre os grupos paramilitares e as forças militares contra a guerrilha das FARC potencializou muitos episódios de violência que culminaram com a migração em massa da população das zonas afetadas por essas incursões (para)militares. Mesmo assim, a violência não desapareceu com o Acordo de Paz. Ela segue como uma ameaça ou realidade constante em diversas regiões do país. Por isso, pensar a necessidade de reparação e superação da condição de vítimas do conflito é fundamental para que essas pessoas possam, inclusive, retornar aos seus lares em paz e com condições estruturais de viver ali com suas famílias.

É necessário, portanto, observar até que ponto os programas de reparação e justiça tem alçado contribuir para a superação real da condição de deslocadas, logo, envoltas em pobreza, vulnerabilidade social e, em alguns casos, indigência das mulheres na Colômbia. Quando dizemos transformação da sua situação de pobreza, não nos referimos apenas às políticas de assistência e/ou ajuda humanitária, estamos falando de projetos políticos que efetivamente tenham por objetivo contribuir para o desenvolvimento socioeconômico deste setor da sociedade. 
Eu só desejo que meus filhos não sofram o que eu sofri”: memórias de dor e resistência de mulheres sobreviventes...

\section{Referências}

Alto Comisionado de las Naciones Unidas para los Refugiados -ACNUR-. (2007). Desplazamiento Forzado en Colombia: derechos, acceso a la justicia y reparaciones. Recuperado de http://www.acnur.es/PDF/6922_20120402135634.pdf

Amnistía Internacional. (2011). “Eso es lo que nosotras exigimos. Que se haga justicia”. Impunidad por actos de violencia sexual cometidos contra mujeres en el conflicto armado de Colombia. Recuperado de http://www.acnur.org/fileadmin/scripts/doc.php?file=fileadmin/Documentos/ Publicaciones / 2011/7651

Bello, M. N. (2000). Las familias desplazadas por la violencia: un tránsito abrupto del campo a la ciudad. Revista de Trabajo Social, 2, 113-123.

Centro Nacional de Memoria Histórica-CNMH-. (2012). El Placer. Mujeres, coca y guerra en el Bajo Putumayo. Bogotá, Colombia: Taurus.

Centro Nacional de Memoria Histórica -CNMH-. (2013). ¡Basta ya! Colombia: Memorias de guerra y dignidad. Bogotá, Colombia: Imprenta Nacional.

Clausewitz, C. V. (2014). Da Guerra. São Paulo, Brasil: Martins Fontes.

Consultoría para los Derechos Humanos y el Desplazamiento Forzado- CODHES. (2008). Los límites de la guerra. Conflicto, derechos humanos y desplazamiento forzado en el sur oriente colombiano. Recuperado de http://www.codhes.org/ codhes/images/biblioteca/ DocCODHES10-LimitesGuerra.pdf

Corte Constitucional. (2008). Auto 092/08. Recuperado de http:/ /www.corteconstitucional. gov.co/relatoria/autos/2008/a092-08.htm

Corte Constitucional. (2015). Auto 009 de 2015. Recuperado de http://www. corteconstitucional.gov.co/T-025-04/AUTOS\%202015/Auto\%20009\%20del\%20 $27 \% 20 \mathrm{de} \% 20$ enero\%20de\%202015seguimiento\%20ordenes\%202\%20y\%203\%20 del\%20auto\%20092-08.pdf

Gómez, D. y Wills, M. E. (2012). Los movimientos sociales de mujeres (1970-2005). Innovaciones, estancamientos y nuevas apuestas. En S. Astorga., M. Ayala. y E. Campos. (Eds.), Historia Contemporánea de Colombia. Conflicto Armado, régimen político y movimientos sociales. Bogotá, Colombia: Editorial Norma.

Ley 387 de 1997. (18 de julio). Por la cual se adoptan medidas para la prevención del desplazamiento forzado; la atención, protección, consolidación y estabilización socieconómica de los desplazados internos por la violencia en la República de Colombia. Diario Oficial N. 43.091. 
Meertens, D. (1995). La paz: miradas de esperanza. Bogotá, Colombia: Pontificia Universidad Javeriana.

Meertens, D. (2000). Ensayos sobre tierra, violencia y género: hombres y mujeres en la historia rural de Colombia (1930-1990). Bogotá, Colombia: Universidad Nacional de Colombia, Centro de Estudios Sociales.

Rapoport, A. (2014). Da Guerra. São Paulo, Brazil: Martins Fontes.

Restrepo, O. C. (2007). ¿El silencio de las inocentes?:Violencia sexual a mujeres en el contexto del conflicto armado. Opinión Jurídica, 6 (11), 87-114.

Saldarriaga, N. I. (Coord.). (2013). Mujer, negra y desplazada: triple victimización en Colombia. Medellín, Colombia: Ediciones UNAULA.

Sánchez, G. (2012). Guerra prolongada y negociaciones inciertas en Colombia. En S. Astorga., M. Ayala. y E. Campos. (Eds.), Historia Contemporánea de Colombia. Conflicto Armado, régimen político y movimientos sociales (pp. 17-71). Bogotá, Colombia: Editorial Norma.

Schmitt, C. (1992). O conceito do político. São Paulo, Brazil: Ed. Vozes.

Segato, R. L. (2014). Las nuevas formas de la guerra y el cuerpo de las mujeres. Revista Sociedade e Estado, 29 (2), 341-371.

Segura, N. y Meertens, D. (1997). Desarraigo, género y desplazamiento interno en Colombia. Nueva Sociedad, 148, 30-43.

Unidad de Atención y Reparación Integral a las Víctimas -UARIV-. (2011). Mujeres y conflicto armado. Recuperado de https://previa.uclm.es/fundacion/resolucionConflictos/pdf/ enlaces/XinformeViolencia.pdf

Žižek, S. (2014). Violência: seis reflexões laterais. São Paulo, Brasil: Boitempo. 